\title{
Modulation of mid-IR radiation by a gated graphene on ferroelectric substrate
}

\author{
Strikha M.V.
}

V. Lashkariov Institute of Semiconductor Physics, National Academy of Sciences of Ukraine, 45 Nauka Ave., 03650 Kyiv-28, Ukraine, maksym_strikha@hotmail.com

Received: 20.09 .2011

\begin{abstract}
We demonstrate theoretically a possibility for modulation of mid-IR radiation by low-voltage gated single/multilayer graphene placed on ferroelectric $\mathrm{Pb}\left[\mathrm{Zr}_{(\mathrm{x})} \mathrm{Ti}_{(1-\mathrm{x})}\right] \mathrm{O}_{3}$ (PZT) substrate. In the range of gate voltages where thin epitaxial PZT films behave as high-permittivity dielectrics, the modulation depth for the case of five-layer graphene can be as high as $10 \%$.
\end{abstract}

Keywords: graphene, ferroelectrics, modulation of optical radiation

PACS: $78.67 . \mathrm{Wj}, 42.79 . \mathrm{Hp}$

UDC: 535

\section{Introduction}

A graphene-based optical modulator for near-IR range $(1.35-1.6 \mu \mathrm{m})$ has first been developed in the work [1]. It has been demonstrated that the modulator can be promising for many devices with on-chip optical interconnections. Concerning its modulation efficiency, it can be already comparable to, if not better than, the modulators based on traditional semiconductor materials such as $\mathrm{Si}$, $\mathrm{GeSi}$ and InGaAs, of which geometrical size is orders of magnitude larger. In this work a singlelayer graphene has been placed on a $7 \mathrm{~nm}$ thick $\mathrm{Al}_{2} \mathrm{O}_{3}$ substrate over Si gate, which has also served as a waveguide for the near-IR radiation. The footprint of the present device is as small as $25 \mu \mathrm{m}^{2}$, while the operation speed remains as high as $1.2 \mathrm{GHz}$.

A general theory for carrier-induced modulation of radiation by a gated graphene has been worked out in the study [2]. There it has been shown that the contribution of carriers essentially modifies the response of graphene due to Pauli-blocking effect, provided that the absorption is suppressed at $\hbar \omega / 2<E_{F}$ (with $E_{F}$ being the Fermi energy). At low temperatures or high doping levels, the threshold frequency at which the absorption jumps up and the effect becomes notable is determined by the condition

$$
\hbar \omega_{t h}=2 E_{F} \sim \sqrt{n}
$$

where the concentration $n$ depends linearly on the gate voltage $V_{g}$ and the substrate permittivity $\kappa$ and is inversely proportional to the substrate width $d$ :

$$
n\left(\mathrm{~cm}^{-2}\right)=7.2 \times 10^{10} \frac{300}{d(\mathrm{~nm})} \frac{\kappa}{3.9} V_{g}(\mathrm{~V}) .
$$

The figures appearing in Eq. (2) are normalised to the characteristics of a $300 \mathrm{~nm}$ thick $\mathrm{SiO}_{2}$ substrate employed in the first graphene-related work [3]. However, use of high- $\kappa$ substrates (AIN, $\mathrm{Al}_{2} \mathrm{O}_{3}, \mathrm{HfO}_{2}, \mathrm{ZrO}_{2}$, etc.) enables obtaining higher concentrations for the same gate voltages (see, e.g., the work [4]). This is important because, for the threshold wavelength $\lambda_{\text {th }}$ corresponding to the threshold frequency given by Eq. (1), Eqs. (1) and (2) yield in 


$$
\lambda_{t h} \sim \sqrt{\frac{d}{V_{g}}} \equiv \frac{1}{\sqrt{E_{s}}},
$$

where $E_{\mathrm{s}}$ stands for the homogeneous gate-induced electric field intensity in the substrate. Eq. (3) implies that, in order to get the modulation effect for shorter radiation wavelengths (e. g., in the visible range), one needs stronger fields (and so higher gate voltages), which finally can cause breakdown of the substrate.

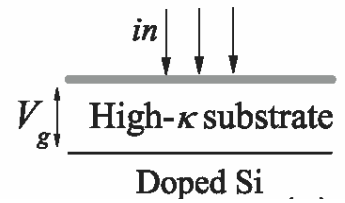

Fig. 1. Single-layer/multilayer graphene placed over a high-k substrate on $\mathrm{Si}$ gate $\left(V_{\mathrm{g}}\right.$ is a gate voltage applied)

The calculations performed in the study [2] have revealed that the modulator suitable for the telecommunication near-IR region $(\sim 1.5 \mu \mathrm{m})$ can be based on single-layer or multilayer graphene placed over a high- $\kappa$ substrate (in fact, this is the case practically realised in [1] - see Fig. 1). Then the efficient modulation can be achieved for the applied fields $\sim 5 \mathrm{MV} / \mathrm{cm}$. In the case of low- $\kappa$ $\mathrm{SiO}_{2}$ substrates, the field should be essentially stronger $(\sim 20 \mathrm{MV} / \mathrm{cm})$, which becomes comparable with the breakdown value. The highest $E_{\mathrm{s}}$ values reached in the study [1] have been in fact of the order of $5 \mathrm{MV} / \mathrm{cm}$. However, this has needed extremely high accuracy when preparing substrates (in the above example, a $7 \mathrm{~nm}$ thick $\mathrm{Al}_{2} \mathrm{O}_{3}$ substrate has been deposited over the Si gate serving also as a waveguide, by the atom layer deposition).

\section{Mid-IR modulation}

The use of ferroelectric substrates with extremely high permittivities can be fruitful for a further developing the gated graphene-based modulators. Graphene placed on such the substrates has been intensively studied in the recent years (see, e.g., [5-7]). An unusual hysteresis in the resistance has been found to occur in the gate sweeps at high voltages, due to ferroelectric properties of the substrates. However, the epitaxial ferroelectric thin films of $\mathrm{Pb}\left(\mathrm{Zr}_{\mathrm{x}} \mathrm{Ti}_{1-\mathrm{x}}\right) \mathrm{O}_{3}(\mathrm{PZT})$ behave as high- $\kappa$ dielectrics at low voltages $\left(V<V_{\text {cr }} \sim 1-2 \mathrm{~V}\right)$, with $\kappa=73(\mathrm{x}=0.2$ [5]) or even $\kappa=400(x=0.3)$ [6]. This should allow one to use them in low-voltage mid-IR gated graphene-based modulators.

The critical value of the field in the PZT substrate, under which the substrate still behaves as a high- $\kappa$ dielectric, can be obtained from the data reported in the work [5] ( $\left.d=300 \mathrm{~nm}, V_{\mathrm{cr}} \sim 2 \mathrm{~V}\right)$ and [6] $\left(d=360 \mathrm{~nm}, V_{\text {cr }} \sim 1 \mathrm{~V}\right)$. This yields $E_{\mathrm{cr}}=67 \mathrm{kV} / \mathrm{cm}(\mathrm{x}=0.2)$ or $E_{\mathrm{cr}}=28 \mathrm{kV} / \mathrm{cm}(x=0.3)$.

Fig. 2 represents a dependence of the threshold wavelength (see Eq. (3)) on the field occurring in the substrate for a number of different substrates: $\mathrm{SiO}_{2}$ (curve 1), $\mathrm{Al}_{2} \mathrm{O}_{3}$ (curve 2), $\mathrm{ZrO}_{2}$ (curve 3), PZT ( $x=0.2$, curve 4), and PZT ( $x=0.3$, curve 5). As seen from Fig. 2, the fields for the PZT that correspond to $\lambda_{\text {th }}$ in the case of telecommunication region ( $\lambda=1.55 \mu \mathrm{m}$, horizontal line) are several times higher than $E_{\mathrm{cr}}$. However, the modulation for the mid-IR range (namely, for the $\mathrm{CO}_{2}$ laser wavelength of $\lambda=10.6 \mu \mathrm{m}$ ) can be facilitated for the fields essentially lower than $E_{\mathrm{cr}}$, when the PZT behaves as a high- $\kappa$ dielectric with the extremely high permittivity.

The transmission and reflection coefficients for the system consisting of a graphene layer, PZT substrate and a Si gate are introduced as (see [2])

$$
T_{\lambda}=\sqrt{\kappa_{S i}(\lambda)} \frac{\left|E_{t}\right|^{2}}{E_{\text {in }}^{2}}, \quad R_{\lambda}=\frac{\left|E_{r}\right|^{2}}{E_{\text {in }}^{2}} .
$$




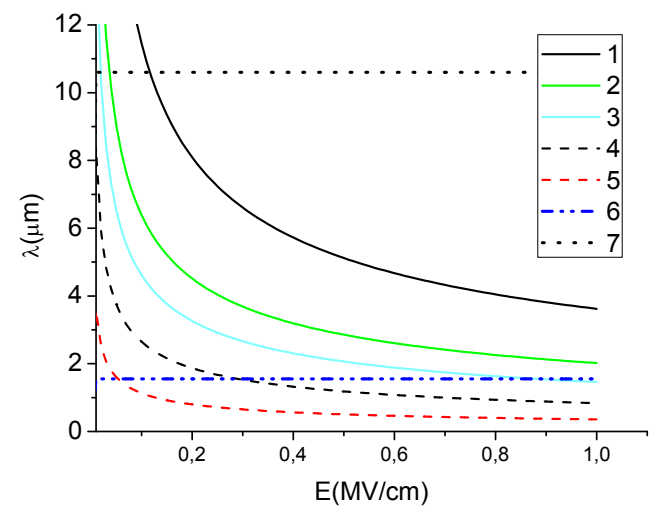

Fig. 2. Dependence of threshold wavelength on the field in substrate for different substrates: $\mathrm{SiO}_{2}$ (curve 1), $\mathrm{Al}_{2} \mathrm{O}_{3}$ (curve 2), $\mathrm{ZrO}_{2}$ (curve 3), $\mathrm{PZT}(x=0.2$, curve 4), $\mathrm{PZT}(x=0.3$, curve 5). Lines 6 and 7 correspond to the wavelengths of 1.55 and $10.6 \mu \mathrm{m}$, respectively.

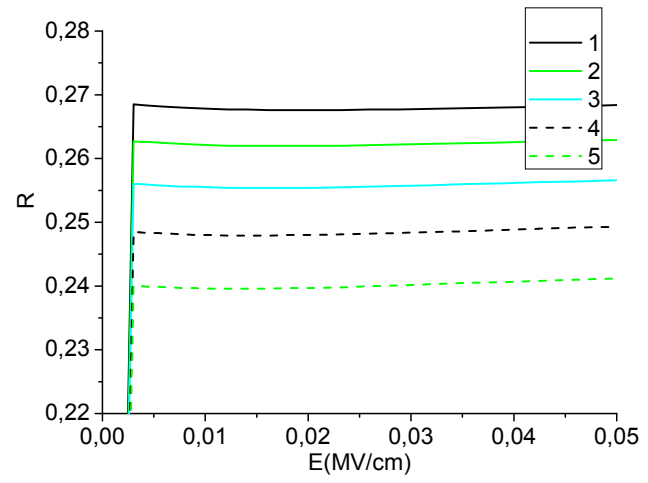

(a)

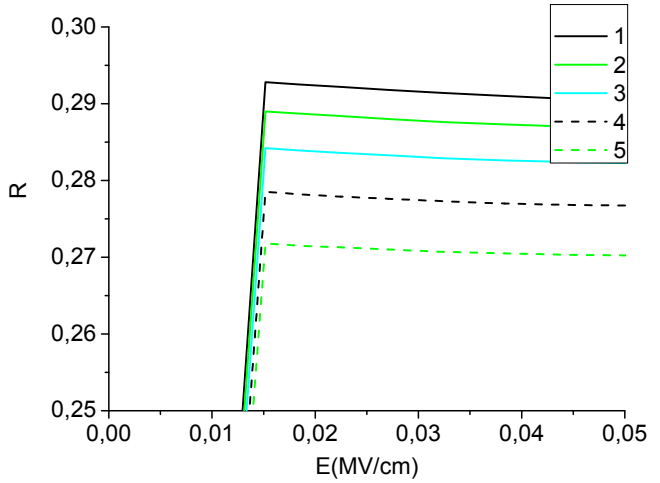

(b)

Fig. 3. Dependence of reflectivity $R$ at the wavelength $10.6 \mu \mathrm{m}$ on the in-substrate field $E$ at room temperature for different substrate thicknesses (curve $1-240,2-280,3-320,4-360$, and $5-400 \mathrm{~nm}$ ). Figures (a) and (b) correspond to single-layer and five-layer graphene, respectively.

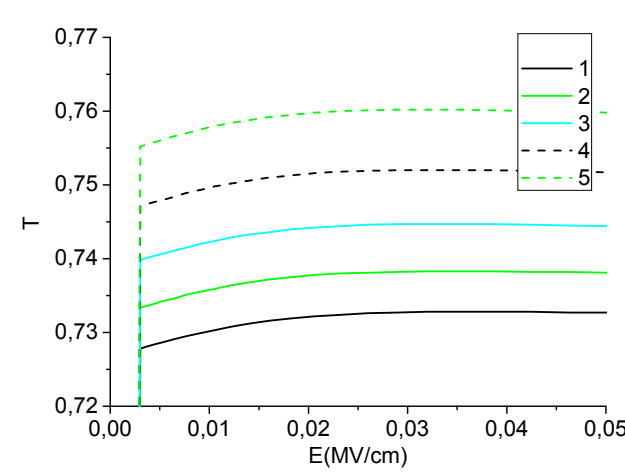

(a)

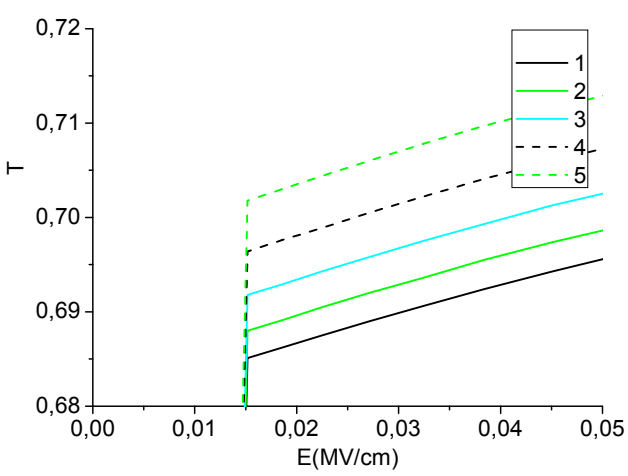

(b)

Fig. 4. Dependence of transmittance $T$ at the wavelength of $10.6 \mu \mathrm{m}$ on the in-substrate field $E$ at room temperature for different substrate thicknesses (curve 1-240, $2-280,3-320,4-360$, and $5-400 \mathrm{~nm}$ ). Figures (a) and (b) correspond to single-layer and five-layer graphene, respectively.

Here $\kappa$ is the permittivity of the Si gate, which is wavelength-dependent. The interrelations between the amplitudes $E$ of the incident wave (the subscript 'in'), the wave back-reflected into vacuum (the subscript ' $r$ '), and the wave transmitted into the Si gate (the subscript ' $t$ ') may be obtained in a manner similar to that used in [2]. It comprises solving the system of wave equations in 
vacuum, a substrate and a gate, with employing proper boundary conditions, and taking into consideration the absorption due to interband transitions associated with carriers in the graphene layer. The coefficients mentioned above have been calculated for both the single-layer and five-layer graphene placed on the PZT substrates $(x=0.3)$. The corresponding dependences are presented in Fig. 3 and Fig. 4 for the films of different thicknesses (240, 280, 320, 360, and $400 \mathrm{~nm})$. The dielectric permittivity of the PZT at $\lambda=10.6 \mu \mathrm{m}$ has been taken to be equal to 5 (see [8]).

As one can easily see from Fig. 3 and Fig. 4, the absorption jumps observed at $\sim 2.5-3.0 \mathrm{kV} / \mathrm{cm}$ (for the single-layer case) and $\sim 13-15 \mathrm{kV} / \mathrm{cm}$ (for the five-layer case) for the graphene placed on the PZT with $x=0.3$ (for which the permittivity is several times higher than that of the PZT with $x=0.2$ ) result in essential jumps observed in both the reflectance and transmittance. The modulation depth can be of the order of $20 \%$ for the fields much lower than the critical ones, at which ferroelectric hysteretic phenomena start to occur.

\section{Concluding remarks}

The results obtained in the present study clearly demonstrate a possibility for fabrication of lowvoltage modulators for the mid-IR range, which are based on the gated graphene placed on the ferroelectric PZT substrate. When compared with the modulator developed in the work [1] which employs an atomically deposited $7 \mathrm{~nm}$ thick $\mathrm{Al}_{2} \mathrm{O}_{3}$ substrate, our modulator reveals the advantage related to comparative simplicity of preparation of the substrates based on epitaxial PZT films. Our device can potentially operate at $500 \mathrm{GHz}$, because the typical characteristic times of speedlimiting processes associated with the recombination and generation of carriers in graphene are in the range of picoseconds.

The modulation in the near-IR range can be based on the same mechanism, though it should make use of the PZT substrates with higher $\kappa$ values. It is known that the PZT features extremely large $\kappa$ at the morphotropic phase boundary occurring near $x=0.52$ [9]. The dielectric constant of the PZT can become as high as 3850 , depending upon orientation and doping. In particular, the authors of the study [7] have observed the value of $\kappa=2000$ owing to substitutional doping of $\mathrm{Pb}$ by $\mathrm{La}$ and fine tuning of the ratio between $\mathrm{Zr}$ and Ti. Such a value should be quite sufficient for the near-IR modulation.

The results obtained by us should stimulate further experimental studies of electrooptic modulation in the near- and mid-IR ranges, using the structures of single-layer or multilayer graphene placed on ferroelectric substrates.

\section{Acknowledgment}

This work was supported by the State Fundamental Research Fund of Ukraine under Grant 40.2/069. Author is grateful to professor Fedir Vasko for fruitful discussions.

\section{References}

1. Ming Liu, Xiaobo Yin, Erik Ulin-Avila Baisong Geng, Thomas Zentgraf, Long Ju, Feng Wang and Xiang Zhang, 2011. A graphene-based broadband optical modulator. Nature. 474: 64-67.

2. Strikha M V and Vasko F T, 2011. Carrier induced modulation of radiation by a gated graphene. J. Appl. Phys. 110: 083106.

3. Novoselov K S, Geim A K, Morozov S V, Jiang D, Zhang Y, Dubonos S V, Grigorieva I V and Firsov A A, 2004. Electric field effect in atomically thin carbon films. Science. 306: 666669.

4. Annirudha Konar, Tian Fang and Depdeep Jena. Effect of high- $\kappa$ gate dielectrics on charge transport in graphene-based field effect transistors. arXiv:0902.0819v2 (15 Oct 2010). 
5. Hong X, Hoffman J, Posadas A, Zou K, Ahn C H and Zhu J, 2010. Unusual resistance hysteresis in n-layer graphene field effect transistors fabricated on ferroelectric $\mathrm{Pb}\left(\mathrm{Zr}_{0.2} \mathrm{Ti}_{0.8}\right) \mathrm{O}_{3}$. Appl. Phys. Lett. 97: 033114.

6. Yi Zheng, Guang-Xin Ni, Chee-Tat Toh, Chin-Yaw Tan, Kui Yao and Barbaros Özyilmaz, 2010. Graphene field effect transistors with ferroelectric gating. Phys. Rev. Lett. 105: 166602.

7. Yi Zheng, Guang-Xin Ni, Sukang Bae, Chun-Xiao Cong, Orhan Kahya, Chee-Tat Toh, Hye Ri Kim, Danho Im, Ting Yu, Jong Hyun Ahn, Byung Hee Hong and Barbaros Özyilmaz, 2011. Wafer scale graphene/ferroelectric hybrid devices for low voltage electronics. Europ. Phys. Lett. 93: 17002.

8. http://refractiveindex.info/?group=CRYSTALS\&material=PbTiO3.

9. Rouquette J, Haines J, Bornand V, Pintard M, Papet Ph, Bousquet C, Konczewicz L, Gorelli F A and Hull S, 2004. Pressure tuning of the morphotropic phase boundary in piezoelectric lead zirconate titanate. Phys. Rev. B. 70 (1): 014108.

Strikha M.V., 2011. Modulation of mid-IR radiation by a gated graphene on ferroelectric substrate. Ukr.J.Phys.Opt. 12: 161-165.

Анотація. Теоретично показано можливість модуляиії випромінювання середнього ІЧ-діапазону одно- чи багатошаровим графеном на сегнетоелектричній підкладиі $\mathrm{Pb}\left[\mathrm{Zr}_{(\mathrm{x})} \mathrm{Ti}_{(1-\mathrm{x})}\right] \mathrm{O}_{3}(P Z T)$ при низьких напругах на затворі. Глибина модуляції для 5-царового графену в діапазоні напруг на затворі, у якому тонка плівка PZT поводиться як діелектрик з дуже високою діелектричною проникністю, становить порядку 10\%. 